\title{
Lexical Cohesion in Oral English
}

\author{
ShuXuan $\mathrm{Wu}$ \\ English Department, Qingdao University of Science and Technology, Qingdao, China \\ Email: shuxuanwu78@163.com
}

\begin{abstract}
Based on Halliday's cohesion theory, this study intends to explore the relationship between lexical cohesion and oral English quality. The author makes comparisons between High Quality Discourses (HQDs) and Low Quality Discourses (LQDs) from the perspective of lexical cohesion. Quantitative and qualitative analyses are used to study the different distribution and failures of cohesive devices in these two groups of discourses.
\end{abstract}

Index Terms - cohesion, lexical cohesion, oral English

\section{INTRODUCTION}

As a basic means of communication, oral English proves to be the hardest skill to acquire. The traditional oral language teaching always focuses on the phonology, lexis and syntax level. However, the lexical cohesive failures of college students in discourse level are given little concern. On the current, domestic and international studies on lexical cohesion are mainly confined in written texts, and there is little research on the lexical cohesion in oral discourses. Domestically, Zhang Delu (2006: 1) makes a survey on the cohesion mechanism of the oral discourses of college students, and proposes corresponding teaching strategies and methods. This study intends to explore the relationship between lexical cohesion and oral English quality through data analysis.

\section{COHESION AND LEXICAL COHESION}

Cohesion was coined by Halliday in 1964. Cohesion occurs when the interpretation of one element is dependent upon another one in the text. Cohesion plays a special role in the creation of text because it can provide continuity that exists between one part of a text and another. And readers or listeners can rely on the continuity provided by cohesion to fill in the missing information, which are not present in the text but are necessary to its interpretation. Halliday points out repeatedly in his book the fact that it is the underlying semantic relation that actual has the cohesive power rather than the particular cohesive marker (1976:229). Nevertheless, he insists that it is the presence of the cohesive markers that constitute the texture.

Lexical cohesion is the most advanced cohesive means and thus the most difficult one to grasp. According to Halliday \& Hasan (2001:287), "lexical cohesion is a cover term for the cohesion that results from the co-occurrence of lexical items that are in some way or other typically associated with one another, because they tend to co-occur in similar environment". The cohesive effect of lexical cohesion is achieved when two or more lexical items within a sentence or across sentence boundaries are associated with each other. The association may be one of related or equivalent meaning or may be one of contrast or may be one of co-occurrence.

Since the present study is a descriptive analysis of the different use of lexical cohesion between HQDs and LQDs, a working taxonomy of lexical cohesion should be suggested first. Lexical cohesion in this paper, mainly based on the taxonomy of Halliday and Hasan, is subdivided into six types: 1) Repetition 2) Synonymy 3) Antonymy 4) Superordinate 5) General noun 6) Collocation. This paper focuses on lexical cohesion across sentence boundaries, while that within a sentence is not explored.

\section{RESEARCH DESIGN}

\section{A. Objectives}

1) What are the differences between HQDs and LQDs in respect of lexical cohesion?

2) What is the relationship between lexical cohesion and oral discourse quality?

3) What are the typical cohesive failures of English-major students?

\section{B. Samples}

This study selects 10 samples among 118 pieces sound recordings of final oral examination of second year English-major students in Qingdao University of Science and Technology. These samples are divided into two groups: five student discourses with higher quality and five ones with lower quality. The time allowed for the oral discourse was five minutes, and their speaking activity happened in an examination situation without the help of dictionaries and other reference books. We may well assume that these students have demonstrated their full competence in oral English in order to get a higher score. 


\section{RESUlTS AND DisCUSSION}

\section{A. Quantitative Analysis}

TABLE 1

MEAN TIES PER SENTENCE

\begin{tabular}{|c|c|c|c|c|}
\hline \multirow{2}{*}{$\begin{array}{l}\text { Types of samples } \\
\text { Lexical devices }\end{array}$} & \multicolumn{2}{|c|}{ HQDs (A) } & \multicolumn{2}{|c|}{ LQDs (A) } \\
\hline & $\mathrm{F}$ & $\%$ & $\mathrm{~F}$ & $\%$ \\
\hline Repetition & 68.6 & $68.78 \%$ & 53.8 & $73.1 \%$ \\
\hline Synonymy & 4.2 & $4.54 \%$ & 4.2 & $5.64 \%$ \\
\hline Antonymy & 1 & $1.2 \%$ & 1.8 & $2.76 \%$ \\
\hline Superordinate & 2.8 & $2.9 \%$ & 3.6 & $3.78 \%$ \\
\hline General nouns & 12.8 & $11.86 \%$ & 6.6 & $9.14 \%$ \\
\hline Collocation & 6.6 & $7.96 \%$ & 5.6 & $5.6 \%$ \\
\hline Total lexical ties & 96 & $100 \%$ & 73.4 & $100 \%$ \\
\hline Total number of sentences & 42.8 & & 40.4 & \\
\hline Mean ties per sentence & 2.24 & & 1.82 & \\
\hline
\end{tabular}

1) By calculation, mean ties per sentence employed by HQDs and LQDs are 2.24 and 1.82 respectively, the mean ties per sentence employed by HQDs is higher, therefore, we can safely conclude that lexical cohesion is, to some degree, positively correlated with oral English quality.

2) Table 1 also demonstrates that among all the lexical subtypes employed by the two types of discourses, repetition is most frequently used, making up more than $68 \%$ of the total ties. Other kinds of lexical cohesion are rarely employed in these two discourses.

In order to gain a more comprehensive interpretation of lexical cohesion and its significance with Oral English quality, the author also provides a qualitative analysis of the tagging result.

\section{B. Qualitative Analysis}

A detailed description of the differences in using 6 types of cohesive devices will be illustrated respectively.

\section{Repetition}

In order to have a clearer interpretation of the difference, repetition in this study is divided into two parts: simple repetition and complex repetition. To avoid the difference of topic and length of the discourse sample, the author chose HQD5 and LQD3, which has the same topic: part-time job and similar length, as the research samples for this question.

TABLE 2

THE TAgGing RESUlt OF SIMPLE REPETITION TERMS

\begin{tabular}{|c|c|c|c|c|}
\hline Serial & Repetition terms & Simple Repetition NO. & LQD3 $\quad$ Repetition terms & Simple Repetition NO. \\
\hline 1 & part-time job & 10 & part-time job & 10 \\
\hline 2 & think & 10 & think & 8 \\
\hline 3 & college & 10 & college & 7 \\
\hline 4 & spare time & 5 & time & 3 \\
\hline 5 & money & 5 & spend & 3 \\
\hline 6 & Study & 5 & task & 2 \\
\hline 7 & get & 4 & balance & 2 \\
\hline 8 & necessary & 3 & opinion & 2 \\
\hline 9 & things & 3 & point & 2 \\
\hline 10 & foreign language & 2 & pocket money & 1 \\
\hline 11 & society & 2 & concentrate & 1 \\
\hline 12 & playing & 2 & knowledge & 1 \\
\hline 13 & waste & 2 & necessary & 1 \\
\hline 14 & reason & 2 & important & 1 \\
\hline 15 & important & 2 & school & 1 \\
\hline 16 & life & 2 & relationship & 1 \\
\hline 17 & looking & 1 & support & 1 \\
\hline 18 & computer games & 1 & work & 1 \\
\hline 19 & difficult & 1 & energy & 1 \\
\hline 20 & fact & 1 & & \\
\hline 21 & university & 1 & & \\
\hline 22 & number & 1 & & \\
\hline 23 & opinion & 1 & & \\
\hline 24 & name & 1 & & \\
\hline 25 & well & 1 & & \\
\hline Total & 25 & 78 & 19 & 49 \\
\hline
\end{tabular}


Firstly, the tagging result of repetition shows that the lexical items concerning the topic are most frequently repeated. For example, part-time job and college are repeated most frequently. Generally speaking, repetition of topic words devotes to coherence of a text; for these words are just the point of each passage, so there is no doubt that they run through the whole text and have the highest frequency.

Secondly, it is also found that the simple repetition items employed by LQDs such as task, balance, support, important, spend and energy are loosely connected with each other in meaning, whereas those employed by HQDs such as part-time job, spare time, money, society, college and university are associated with each other tightly and semantically and thus can contribute to the consistence of developing one central topic.

TABLE 3

THE TAGging RESUlt OF COMPLEX REPETITION TERMS

\begin{tabular}{|c|c|c|c|c|}
\hline \multirow{2}{*}{ Serial } & $\begin{array}{c}\text { HQD5 } \\
\text { Repetition term }\end{array}$ & $\begin{array}{c}\text { Complex Repetition } \\
\text { NO. }\end{array}$ & $\begin{array}{c}\text { LQD3 } \\
\text { Repetition term }\end{array}$ & $\begin{array}{c}\text { Complex Repetition } \\
\text { NO. }\end{array}$ \\
\hline 1 & job-jobs & 16 & Study-studies-studying & 8 \\
\hline 2 & Students-student & 15 & Students-student & 8 \\
\hline 3 & Take-taking & 7 & Take-taking & \\
\hline 4 & family-families & 2 & & \\
\hline 5 & Opinion-opinions & 1 & & \\
\hline 6 & earn-earning & 4 & & \\
\hline 7 & Spend-spending & 2 & 3 & \\
\hline Total & 6 & 47 & & 17 \\
\hline
\end{tabular}

As Table 3 shows, there is great difference in using complex repetition. HQDs show a good mastery of complex repetition. The use of complex repetition only reflects writers' syntactic knowledge. When students do not know what else to say, they often resort to restating what they have already said.

To sum up, Overuse of simple repetition and complex repletion may contribute nothing to textual coherence but piling up the already known information and eventually impairs writing quality for wordiness. In oral English, speaker should usually take care to avoid the clumsiness in discourses. One of the most important ways is to adopt other lexical cohesive devices which can add language variety to the discourse. Repetition of the same item should be avoided unless for clarity or intentional emphasis to achieve special rhetorical effect.

2 Synonymy, Antonymy and Superordinate

TABLE 4

THE TAGGING RESULT OF SYNONYMY TERMS

\begin{tabular}{|c|c|c|c|c|}
\hline \multirow{2}{*}{ Serial } & $\begin{array}{c}\text { HQD4 } \\
\text { Synonymy Terms }\end{array}$ & NO. & $\begin{array}{c}\text { LQD2 } \\
\text { Synonymy Terms }\end{array}$ & NO. \\
\hline 1 & easier...relaxing & 3 & free...easier & 1 \\
\hline 2 & harder...stressful...difficult & 2 & university...college & 1 \\
\hline 3 & summary...conclude & 1 & learn...study & 1 \\
\hline 4 & point...opinion & 1 & spare...free & 1 \\
\hline 5 & give up...drop down & 1 & opinion...think & \\
\hline 6 & earn...gain & 1 & & 5 \\
\hline Total & 6 & 9 & 5 \\
\hline
\end{tabular}

TABLE 5

THE TAGGING RESULT OF ANTONYMY TERMS

\begin{tabular}{|c|c|c|c|c|}
\hline \multirow{2}{*}{ Serial } & $\begin{array}{c}\text { HQD3 } \\
\text { Antonymy Terms }\end{array}$ & NO. & $\begin{array}{c}\text { LQD5 } \\
\text { Antonymy Terms }\end{array}$ & NO. \\
\hline 1 & young....aged/old & 2 & old...young & 1 \\
\hline Total & 1 & 2 & 1 & 1 \\
\hline
\end{tabular}

TABLE 6

THE TAGGING RESUlT OF SUPERORDINATE TERMS

\begin{tabular}{|c|c|c|c|c|}
\hline Serial & $\begin{array}{c}\text { HQD3 } \\
\text { Superordinate Terms }\end{array}$ & NO. & $\begin{array}{c}\text { LQD5 } \\
\text { Superordinate Terms }\end{array}$ & NO. \\
\hline 1 & aged parents/old parents... aged /old people...young people...children & 5 & grandma...grandpa & 4 \\
\hline Total & 1 & 5 & 1 & 2 \\
\hline
\end{tabular}

As Table 4, 5 and 6 display, there is little difference between HQDs and LQDs in use of synonymy, antonymy and superordinate. While effective use of synonymy, antonymy and superordinate is positively related to the quality of Oral English.

One important reason for it lies in students' limited vocabulary, which prevents them to express themselves with specific words. Only competent learners who have perfect commands of lexis could make their discourses colorful, 
expressive as well as coherent, while poor speakers are incapable of using synonymy, antonymy and superordinate to achieve language variety.

Another important reason may be that students learn a word in isolation instead of building up a hierarchical network of the interconnected words. For example, when learning a word body, it should be related with other words like head, hand, feet, eyes, mouth and face. Only in this way, relevant words can be retrieved from the internal lexicon.

\section{General Nouns}

General nouns refer to those words such as people, place and thing, which are mostly vague in meaning and easy to learn. The proper use of general nouns will contribute to the coherence of a text, but the overuse of them will make the meaning of the text ambiguous.

TABLE 7

THE TAGGING RESULT OF GENERAL NOUNS TERMS

\begin{tabular}{|l|l|l|l|l|}
\hline Serial & $\begin{array}{l}\text { HQD4 } \\
\text { General Nouns Terms }\end{array}$ & NO. & $\begin{array}{l}\text { LQDs } \\
\text { General Nouns Terms }\end{array}$ & NO. \\
\hline 1 & do & 2 & do & 3 \\
\hline 2 & thing & 1 & thing & 1 \\
\hline Total & 2 & 3 & 2 & 4 \\
\hline
\end{tabular}

Table 7 shows general nouns are applied almost same in HQDs and LQDs. Here we combine data analysis to make a better understanding of general nouns employed by the two types of discourses.

The researcher finds that general nouns are more effectively used in HQDs. That is, competent student speakers know where a general noun should be used and where a more specific word should be used. For example, in HQD1:

(4-3) and I think the spare time is too difficult to spend for me; I just don't know what I should do in my spare time.

In the above sentence, the word $d o$ is a general noun. Relying on context, readers can easily infer that it refers to spend spare time, this simple language can be interpreted easily and smoothly in the discourse.

Conversely, it is found that general nouns are often overused in LQDs. Incompetent students tend to use general words when they have trouble in expressing more concrete or exact meanings or when they try to avoid making mistakes. For example in LQD 2:

(4-4) But I think because the college provides less class everyday, it provides our studentents more time to do their own business and take activities. Also, they can do their interesting things.

In the above example, the word things is a general noun. Relying on context, the listeners can hardly infer that the word things refers to business or activities, also this interpreting process may annoy listeners. Anyway, the overuse of general noun will impair oral English quality for the vague meaning it conveys. And a better solution is by means of more specific words, which can help speakers to transfer their viewpoints to readers more exactly and explicitly.

\section{Collocation}

Collocation is an important tool to make parts of a text bind together. A collocation might not be limited to a pair of words. It is very common to build up lexical relations by using long cohesive chains throughout the whole text. Generally speaking, the longer a collocation chain is, the stronger the cohesive effect is achieved, because longer collocation chain can devote to the expansion of a topic. Therefore, collocation plays a crucial role in developing one's viewpoint intensely and acts as a thread of the text.

TABLE 8

THE TAGging RESUlt OF COLLOCATION TERMS

\begin{tabular}{|c|c|c|c|c|}
\hline Serial & $\begin{array}{c}\text { HQD4 } \\
\text { Collocation Terms }\end{array}$ & NO. & $\begin{array}{c}\text { LQD2 } \\
\text { Collocation Terms }\end{array}$ & NO. \\
\hline 1 & Old parents...parents...children ... family ...care...love...home & 6 & $\begin{array}{l}\text { Examinations...college...fewer } \\
\text { examinations...students...class }\end{array}$ & 4 \\
\hline 2 & Students...school...classes...studying...college & 4 & $\begin{array}{c}\text { college } \ldots \text { less class.... students....more } \\
\text { time....activities...teachers }\end{array}$ & 5 \\
\hline 3 & part-time job...money...experience & 2 & & \\
\hline Total & 3 & 12 & 2 & 9 \\
\hline
\end{tabular}

Table 8 clearly demonstrates that HQDs differ from LQDs in using collocation qualitatively. The former group makes a better use of collocations and tends to use more words with greater variety and complexity to produce longer collocation chains than the latter one.

The co-occurrence of related items in the same passage devotes to the consistency in topic and provides texture as well. Conversely, collocations in LQDs are rarely used, even when used, show a lack of accuracy.

\section{Major Findings}

By analysis of 10 discourses of English major students from Qingdao University of Science and Technology, the author explores the relationship between lexical cohesion and oral English quality, and the major findings of this research include:

1) Lexical cohesion are related to oral English quality. The above analysis of the tagging result clearly displays that HQDs differ from LQDs both quantitatively and qualitatively in using lexical cohesion. According to the mean ties per 
sentence employed by the two groups of discourses, we can conclude that the higher the quality of the discourse is, the more cohesive ties are employed.

2) Frequency counts of collocation prove positive evidence to correlate with speaking quality. There is a significant difference between HQDs and LQDs in their collocation competence. Compared with LQDs, HQDs displays greater variety in their choices and the production of collocations in speaking.

3) Although there is no significant difference in using general nouns between HQDs and LQDs, HQDs can use general nouns with more accuracy and complexity.

4) The main cohesive device used by HQDs and LQDs is repetition, while other devices are rarely employed in their oral English. Due to the limitation of vocabulary and the fear to make mistakes, both HQDs and LQDs tend to overuse repetition and general nouns, and the employment of synonymy, antonymy and superordinate is too far from satisfactory.

The author concludes that English major students should improve their use of cohesive devices to make coherent and tightly organized oral discourses. The author also finds that the overuse of repetition and general nouns is a common phenomenon in their oral English, and the use of other types of lexical devices is far from satisfactory. Finally, the study of lexical chain, lexical density, lexical length, lexical interaction and their relationship with oral English quality should deserve more attention in the future research to gain a more comprehensive interpretation of lexical cohesion and oral English quality.

\section{REFERENCES}

[1] Carrell, P. Cohesion Is Not Coherence. TESOL Quarterly 1982, 16/4:479-488.

[2] Enkvist, N. Coherence, Pseudo-coherence and Non-coherence. In J. Oastman(eds.), Cohesion and Semantics. Abo, Finland: Abo Akademi Foundation, 1978.

[3] Halliday. M. A. K, R. Hasan. Cohesion in English.London: Longman, 1976.

[4] Halliday. M. A. K. An Introduction to Functional Grammar. London: Edward Arnold, 1994.

[5] Halliday, M.A.K. \& Hasan, R. Cohesion in English. Beijing: Foreign Language Teaching and Research Press, 2001.

[6] Jiang Jing. "Lexical Density, Lexical Cohesion and Composition Quality". Excellent Thesies and Dissertations Base in China, 2005.

[7] Xu Jinran. A Preliminary Study of College Students' Oral Communicative Competence. School of Foreign Languages of Guizhou Normal University May, 2005. 